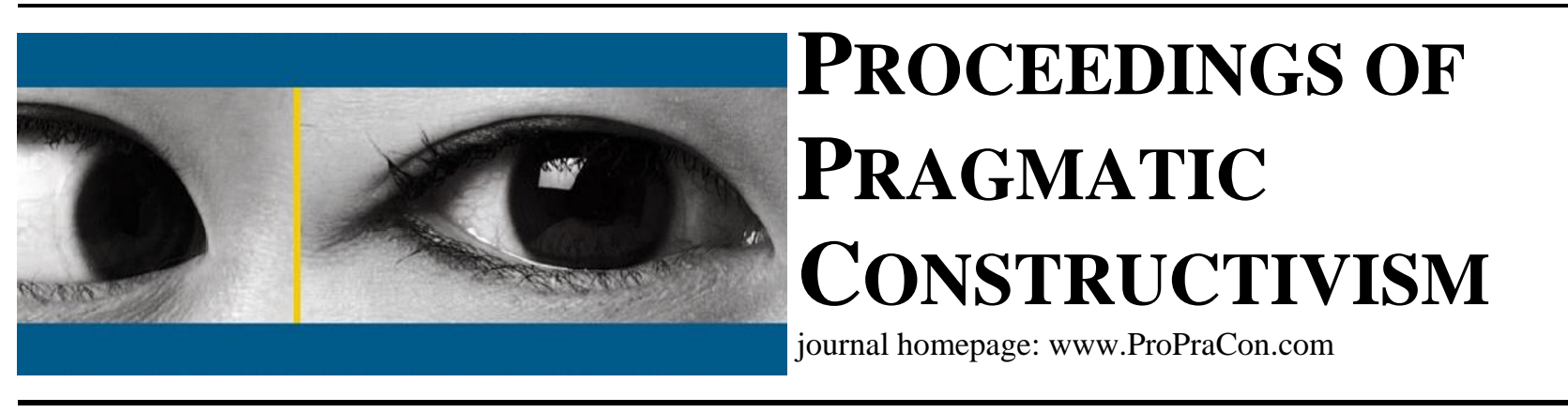

\title{
Understanding performance measurement in public organization under pragmatic constructivism
}

\author{
Lino Cinquini \\ Professor of Management Accounting \\ Scuola Superiore Sant'Anna; Institute of Management \\ Piazza Martiri della Libertà, 24; 56127 Pisa; Italy; l.cinquini@sssup.it \\ Andrea Tenucci \\ Assistant Professor of Management Accounting \\ Scuola Superiore Sant'Anna; Institute of Management \\ Piazza Martiri della Libertà, 24; 56127 Pisa; Italy; a.tenucci@sssup.it \\ Cristina Campanale \\ Research Fellow \\ Scuola Superiore Sant'Anna; Institute of Management \\ Piazza Martiri della Libertà, 24; 56127 Pisa; Italy; c.campanale@sssup.it \\ Emilio Passetti \\ Research Fellow \\ Scuola Superiore Sant'Anna; Institute of Management \\ Piazza Martiri della Libertà, 24; 56127 Pisa; Italy; e.passetti@sssup.it
}

\begin{abstract}
The aim of this paper is twofold. Firstly to explore how a constructivist pragmatic approach may be applied to understand critical aspects of performance measurement in a public organization. And secondly, to contribute in proposing some effective characteristics of the potential PMS in the same setting. To this aims we analyze how different topoi may cohabit in a Regional Authority. This topic is particular important because the convergence of different topoi is crucial for the achievement of common organizational visions and to achieve organizational goals. The investigation of topoi was supported by interviews and focus groups that involved two organizational positions of an Italian Regional Authority: Top Managers and Middle Managers. These two organizational positions were chosen because they perform different types of activities and hence we can expect different topoi. The aim of interviews and focus group was to trace values, facts, logic and communication that form the topos driving the perception of performance. Interviews involved 7 Top Managers in charge of the 7 divisions of the Region and 15 Middle Managers in charge of departments. 17 focus groups involved 90 Middle Managers in charge of responsibility areas under each department.

Results underline that Top Managers and Middle Managers are driven by different topoi and have a different concept of performance at the base of their efforts: Top Managers require flexibility and professionalisms in their work, while Middle Managers require precise plans and rules. The result is that different topoi have different concepts of performance and that the performance of the Regional Authority and the contribution of organizational actors to the achievement of organizational goals result unclear and confused. Findings underline that the alignment of topoi is of utmost importance to the design of an effective PMS in the organization: increasing the communication between these two organizational levels may favor the convergence of the two topoi and increase the clarity of the Regional Authority performance goals and measures.
\end{abstract}

Keywords: performance measurement; public services; pragmatic constructivism. 


\section{Introduction}

Since the '90 several managerial reforms have been introduced in the public sector with the aim to change organizations towards manageriality in the vein of the reform movement known as New Public Management (NPM) (Osborne and Gaebler, 1991; Hood, 1995). NPM led many public organizations to review their procedures and structures and adopt managerial innovations from the private sector, such as Performance Measurement Systems (PMS), as steering mechanisms to translate the principles of the reforms into the organization and comply with them (van Helden, 2005).

However, the private and the public sector are different and the adoption of the business approach in the bureaucratic environment of public organizations is difficult (Lapsley, 2009). This and has often determined a gap between ambition of reforms and actual results (Humphrey et al., 1993; Humprey and Miller, 2011)

With the aim to contribute to deepen the criticalities related to the introduction of PMS in the public sector, this research explores the implementation of a PMS in a regional authority. This research adopts a pragmatic constructivist approach which suits the analysis of PMS in complex organizational settings where the reality is constructed by the different organizational actors. Under the pragmatic constructivist approach analyzing the coherence of different organizational topoi (and the linked perception of performance) with the PMS allows the understanding of the capability of the PMS to drive the organization toward the improvement of services and the achievement of strategic goals. Using this approach, the paper tries to answer the following questions: which are the topoi living in the TRA and the linked perceptions of performance? Are there some integrations or commonalities between these topoi? Are there some elements or conditions which may favor the unitarily of different topoi towards the achievement of organizational goals?

The remainder of the paper is organized as follows: section 2 provides a review of performance measurement issues in the Public Sector; section 3 describes the research approach and section 4 the research context; section 5 presents the findings and, finally, the paper ends with a discussion of the main findings and some concluding remarks.

\section{Performance measurement issues in public sector}

The refinement of management accounting tools and their adaptation to the public context may help to make accounting useful for managerial aims (Lapsley, 2001), but the full understanding of the organizational and social context is required to make accounting tools able to adequately represent reality (Puxty, 1993; Otley, 1999). In this respect, the translation of management accounting devices from private sector to the public, and in particular to the Government, has been subjected to an intense debate (Lapsley, 2001). Several studies have contributed to the debate around the application of such reforms in the public sector and have underlined a gap between reformers' aims and outcome (Arnaboldi and Palermo, 2011; Humphrey et al., 1993; Kurunmaki and Miller, 2006) and hence a failure of MA in translating the principles of reforms in the organization. A recurrent issue in the debate around the implementation of accounting and managerial reforms in the public sector relates to the fact that being the private sector the source of management accounting innovations in the public sector (Likierman, 1994; Bromwich and Lapsley, 1997; Hyndman and Eden, 2000), this resulted in MA tools as a set of monetary measures which are not able to capture the complexity of the public sector where professionalisms and political issues dominate the work (McSweeney, 1994). On this point Arnaboldi and Palermo (2011) suggest that the failure of MA depends on the approach adopted in its introduction, because many organizations have focused only on technique while management accounting is not an issue of technique but rather an issue of role and use of management accounting.

Another issue in the debate around the implementation of accounting and managerial reforms in the public sector concerns ambiguity and its impact on the implementation of innovations in public accounting (Arnaboldi and Lapsley, 2009) and in the implementation and use of PMS (Brignall and Modell, 2000; Modell, 2004; Johnsen, 2006; Vakkuri and Meklin, 2006). Ambiguity derives from the complexity of the public environment where different actors give multiple meanings to reforms and related goals (Matland, 1995) and creates uncertainty with respect to the individuation of the role of the various organizational actors in the individuation, implementation, use and effects of PMS. Another important point underlined by Chapman et al. (2009), is that MA is the result of the interaction between subjects, objectives and external events. Waggoner et al. 1999 have addressed the followings: a) internal influences such as power relationship and dominant coalition interests; (b) degree of top level support (c) process issues such as manner of implementation of management of political processes and (d)) external influences such as legislation.

Internal influences contribute to the complexity of the public sector. In particular Hopwood (1972) and Simons (1991) have underlined the role of internal influences for effective MA implementation and argued that similar accounting techniques may lead to different results depending on different interpretation of organizational actors. 
Internal influences such as power relationship and dominant coalition interests affect the implementation of PMS. In fact, the organization is composed by multiple interests from different organizational actors and are like "political arenas" in which the different groups of actors conflict to determine organizational performance criteria according to their interests (Scott, 1995). Here the most powerful actors determines the outcome of change (Pettigrew and Whipp, 1991) and solves conflicts by the use of power (Pfeffer, 1992; Walsh et al., 1981). Performance will represent the interest of those who comprise the dominant coalition.

Further, the strength of conflicts and resistance are shaped by the culture of individuals and by what individuals inside the organization can gain or lose from a change (Besanko et al., 1996; Ottaway, 1983; Harvey, 1995). Middle and line managers are particularly critical and often consider MA as a merely bureaucratic fulfilment and a mere piece of paper.

In this respect, the role of Top Management emerges as supporter to implement change implementation strategies and motivate lower levels (middle and line managers and employees) (Weiss, 1996; Wright, 2007). Top Management commitment is a pre-requisite for consensus-building and successful implementation of MA, by sharing information with different groups of organizational actors (Modell, 2004; Cavalluzzo and Ittner, 2004; Kaplan, 2011; Poister and Streib, 1995). Wright (2007) emphasizes the importance of communication: in his view Top managers should motivate employees by clearly communicating the importance of the employees' work in contributing to organizational goals. This would increase the motivation of employees because they will feel the importance of their work and tasks, especially when their tasks are clear and understood.

However several problems may arises because Politicians, Top managers and Middle and line managers have different perceptions of MA (Modell, 2004).

Considering politicians, Ter Bogt (2003) has shown how, in Dutch municipalities, elected politicians judge professional managers and their organizations in a 'businesslike' manner. However, they are not interested in concrete and 'objective' data (such as outputs, costs, and efficiency) but they evaluate Top managers' performances on a rather wide range of criteria and subjective impressions.

On the other hand, middle and line managers search for MA tools tightly coupled with actions (Covaleski and Dirsmith, 1981), while Top managers often have the tendency to use MA to ally with political bodies (Brignall and Modell, 2000; Modell, 2004; Klott, 2002; Modell, 2003), instead of using MA for decision making and control. Hence, even if they involve lower levels and assign them goals for decision making, their behavior results hypocritical and tends to create ambiguity. For example, Klott (2002) has found that the excessive dependence of an Australian University manager to politically appointed funding bodies led him to use MA to promote decisions with politicians, instead of using MA for decision making. The effect was that, despite they had a PMS system with multiple performance indicators representing several stakeholders’ interests, lower levels remained skeptical.

In this respect Modell (2004), Llewellyn (1996), Pettersen (2001) and Covaleski and Dirsmith (1981) argue that the involvement of lower levels may offer to them the opportunity to exert pressure on managers to commit themselves to a particular course of action, for example the development of tools more oriented to decision making. Ambiguity may also be reduced by providing a clear linkage between Top Managers and lower levels goals (Covaleski and Dirsmith, 1981; Aidemark, 2011; Modell, 2004).

\section{$3 \quad$ Research Method and Theoretical Framework}

The empirical research presented in the paper has been conducted in Italy in the Tuscany Regional Authority (TRA) using a qualitative approach, supported by interviewees, focus groups and document analysis.

The investigation of PMS in the TRA has been interpreted in the light of a pragmatic constructivism approach, which suits the investigation of the role of Top managers and Middle managers (i.e. actors) in the construction of reality concerning performance measurement. According with the theoretical framework, reality is made by four integrated dimensions (facts, logic, communication and values) and the investigation of these dimensions and the associated beliefs allows to discover how organizational actors construct reality and performance concepts (Nørreklit et al., 2006; Nørreklit et al., 2010; Jakobsen et al., 2011; Seal, 2012; Mitchell et al., 2013).

Qualitative approaches result particularly useful to gather and understand in-depth information about the topic investigated, define future research questions and determine the feasibility of a certain theory/procedure (Yin, 2003; Auerbach and Silverstein, 2003). Data collection involved semi structured interviewees, focus groups and document analysis. 
The interviews have involved 6 Top managers (i.e. the directors) of the 6 divisions of the Region, 12 Middle managers (i.e. the area coordinators) of departments. Focus groups have involved 90 Middle managers (i.e. the sectors managers) divided in 16 groups (each group was meet twice). The division of managers in groups has been made according to the similarities in their activities. In total 8,5 hours of interviews has been made for Top managers, 17,5 hours of interviews for Middle managers and 70 hours of focus groups have been carried out between November 2011 and February 2013. The interviews and the focus groups have addressed four main topics concerning respectively, the activities carried out in each direction and department, the targets associated with the activities, the features and perceived criticalities of the performance measurement system currently in use and finally the features that the new performance measurement system should have.

With respect to the 6 Top managers (i.e. the directors) and 12 Middle managers (i.e. the area coordinators) of departments (see subsequent section) we have preferred individual interviews because the activities they perform are very different. The set of interviews with Top managers and Middle managers have been audio taped and transcribed. Following Yin (2003) and Auerbach and Silverstein (2003) interviews data have been categorized and coded in order to identify relevant aspects able to explain how actors perceived performance measurement reality. All the researchers have independently contributed to data analysis according to this procedure: a leader researchers prepared a first draft of the analysis and this draft was subsequently reviewed, revised and supplemented by the observations of the other researchers.

With respect to the group of 90 Middle managers, focus groups were preferred, instead of individual interviews, because of the high number of interviews and because of the similarity of activities performed. Being activities similar, focus group results a suitable method because the discussion between the member of the group allows a deeper understanding of phenomena and greater insights into the reasons of certain perception of performance and PMS (Bloor et al., 2001).

Two weeks before the first focus group meeting, participants received a short summary of the topics to be discussed, while between the first and second meeting we assigned to each participant a short essay concerning the identification of the features that an ideal performance management system should have in his view. In the second meeting we discussed the short essays prepared by participants with the aim to identify commonalities between the actors and to share key aspects and beliefs concerning performance measurement. During each focus group the researchers took notes of the main observations emerged, which have been further used to identify the reality of performance by actors.

Before conducting the planned interviews and focus groups, a document analysis was conducted. Documents included organization charts, the "Strategic Plan" and the "Plan of Performance" and the linked rewards. They have been important to understand the activities carried out by Top managers and Middle managers, the performance measurement system logic and the characteristics and process of the budgetary and political negotiation.

\section{Research Context}

Public Sector reforms have interested Italy since the beginning of the '90 and have followed a path featured by the institutional context, in which managerial knowledge has been heavily subordinated to a better established juridicallegal framework (Panozzo, 2000). Recently, a new decree (150/2009) has introduced a further challenge in the Italian Public Administrations. This decree imposed to Public Administrations the introduction of a systematic "performance evaluation cycle" both for the organization and for employees, with the aim to improve the provision of services

Public Administrations has been required to plan activities, by defining challenging, controllable and measurable goals, to measure the achievement of goals and to improve the reporting system to increase transparency with respect to stakeholders and citizens. This law has identified precise phases of the "performance evaluation cycles", the characteristics of goals and indicators, the responsibility of managers in contributing to organizational goals and precise rewards.

Tuscany Regional Authority (TRA) has been one of the first regions applying this decree, by the Regional law 57/2010. In the aims of the Decree 150/2009 and the Regional law 57/2010 the identification of an adequate PMS is a fundamental step to achieve the improvement in the provision of services by Public Administrations.

\subsection{The organization of the Tuscany Regional Authority and the elements of complexity}

The Tuscany Regional Authority (TRA), as well as the other Italian Regions, within its autonomy guaranteed by the Italian Constitution, represents the Regional community. It protects the citizens' fundamental rights, such as healthcare, 
work, family etc, by defining priorities, managing funds, planning services, stipulating contracts with external providers (such as municipalities, agencies, companies) and controlling external providers. Several aspects make complex the work of the TRA: the organizational structure of the TRA, the relationships with external entities (municipalities, agencies, service providers, etc.); the influences of politicians. These aspects are represented in the Figure 1.

\section{Figure 1: The element of complexity of the TRA}

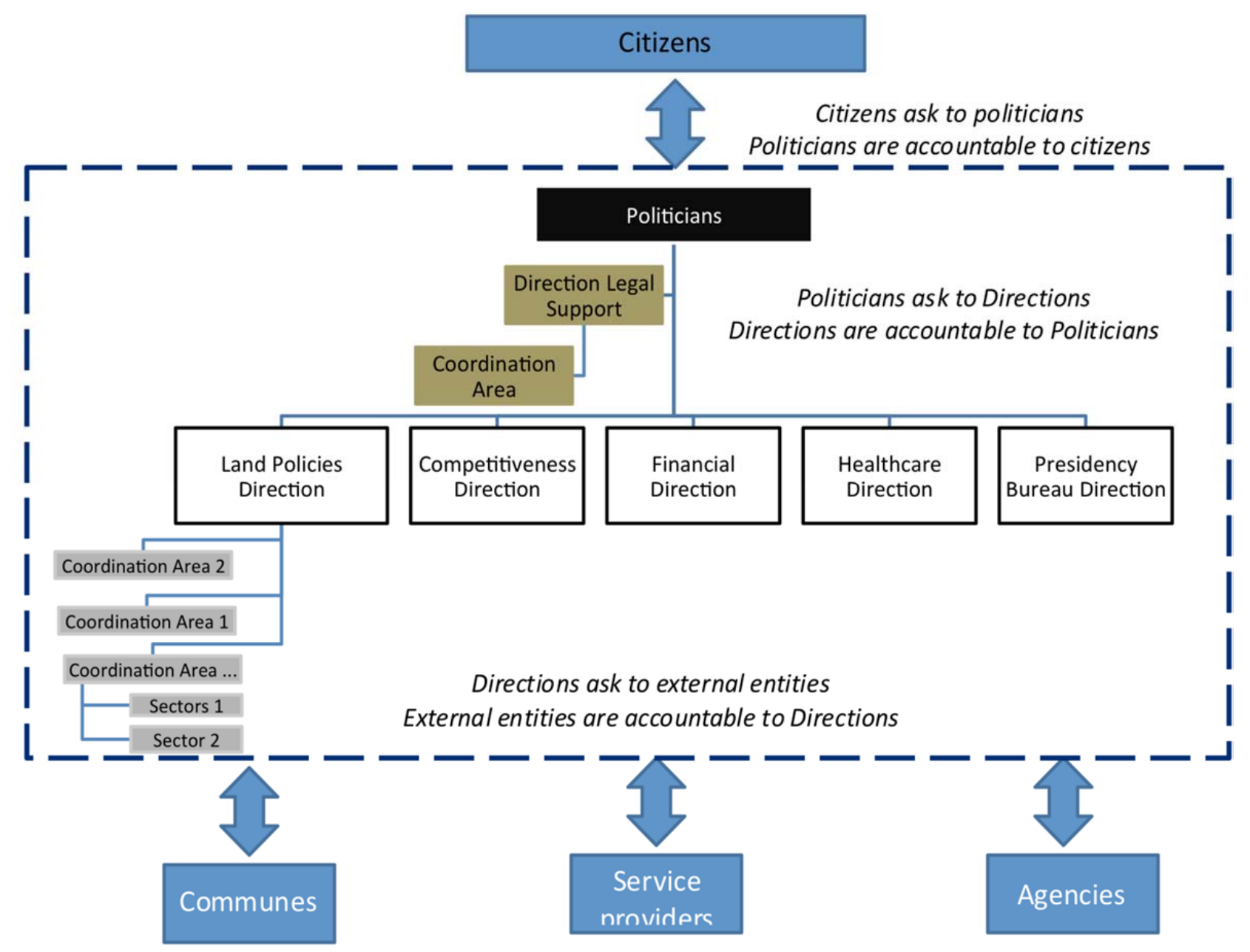

With respect to the organizational structure, the TRA has an articulated organizational structure with decentralized responsibilities. As Figures 1 shows, the organization is hierarchical functional and the Direction "Legal Support" is staff position and provides support to all the other units

The TRA employs about 2.300 employees of whom about 130 are Managers (Top or Middle Managers) and manages more than 11.000 millions of euro per year. It is organized in eight divisions called Directions, managed by a Top Manager, with competences in broad fields (for example infrastructure, environment, healthcare etc). Directions are further divided in Coordination Area and Sectors managed by Middle Managers with competences in specific and more detailed fields. Above there are employees who have lower responsibilities. Both Top and Middle Managers plan and coordinates activities and employees within their unit to assure services to citizens. Directions, Coordination Area and Sectors are autonomous even if several interdependencies exist, for example the construction of a new motorway runs into environmental issues, transportation policies, technical aspects whose competence is of different actors, and this implies an intense interaction between different actors who contribute to processes. The description of the organizational structure underlines the complexity of the TRA composed by multiple decisional levels and numerous interdependencies.

Another element that increases the complexity of the work is the number of relationships with external entities (communes, agencies, service providers, companies). In fact, the Region does not directly provide services but assures the provision of services by defining priorities, managing funds, planning services, stipulating contracts with external 
providers (such as municipalities, agencies, companies), and controlling external providers. Hence, even if the Region is not directly in charge of providing services to citizens, it oversees the efficient and effective development of the whole process.

The influence of politicians also contributes to increase the complexity of the work. Politicians are elected by citizens and hence they are accountable to them: their mission is to answer to citizens and get their consensus in order to assure a long career. This requires capabilities to be flexible because the environment where they work is changing, for example new communitarian directives, natural events, new needs require an adaptation of priorities. On the other side the TRA is accountable to politicians and subjected to the same changes of priorities defined by politicians.

Consequently the TRA has to adapt itself to the new priorities and satisfy the new needs and report results to politicians. The following sentence, by the Vice-President of the TRA, underlines the role of politicians as connection between citizens and the TRA.

"The Region is made of managers and employees and they are important. Our role is to link the external environment, and hence the citizens, to the work that the Region does. We are the eyes and the ears, we have to capture priorities in the external environment and the Region has to recognize and implement these priorities".

\subsection{The performance evaluation system of the Tuscany Regional Authority}

The "performance evaluation cycle”, as described in the Regional Law 57/2010, is supported by two main documents: the "Strategic Plan" and the "Plan of Performance". The Strategic Plan is a triennial document that defines long term strategic goals in terms of outcome, for example "sustain research", "sustain education”, "increase tourisms” etc. These goals are used by politicians to communicate to citizen the results expected at the end of the legislature and to the other organizational actors the aims of the TRA towards which they must converge. These goals are broad their achievement is pursued through activities that are adapted depending on the changes required by the environment. Activities performed to achieve these goals cant' be identified in advance, but they are identified day by day depending on the specific moment.

These strategic goals are annually deployed in the organization through the "Plan of Performance" first to Top Managers, then to Middle Managers and to employees. "Trees of goals" and indicators illustrate the cause-effect relationship between strategic long terms goals and related indicators and annual goals of the different organizational positions. Figure 2 represents an example of "tree of goals” (For higher simplicity indicators are not represented). As this picture shows, the strategic goal "Integration of cultural and touristic policies through innovative sustainable projects at international level” is linked to two goals for Top Managers: "Development of the project Franchigena route" and "Sustainment and promotion of new interventions in the field of the culture". These goals for Top management are linked to further goals for Middle Managers. For example the goal "Development of the project Franchigena route” is linked to the goal "Elaboration of plan” and "Definition of the executive master plan".

\section{Figure 2: Example of “tree of goals"}

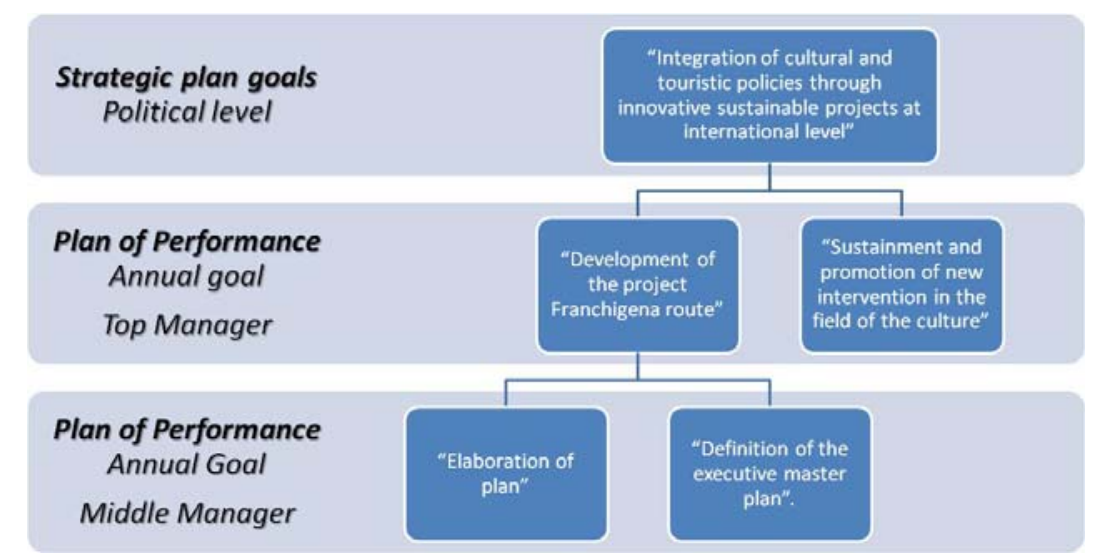


The majority of goals both for Top Managers and Middle Managers are in terms of output, for example number of documents, number of laws etc. Goals in terms of efficiency, i.e. percentage of savings and process, i.e. time, exist. Top Managers also have some indicators in terms of outcome, measured over two or three years.

The annual evaluation of Top and Middle Managers and employees is based on a complex process which includes different parameters: the contribution to the achievement of strategic goals, the achievement of assigned and individual goals and behaviors. The manager of the higher grade makes the evaluation: for example the head of the Coordination Area is evaluated by the head of the Direction and evaluates the head of the Sector; politicians evaluate the head of the Direction. All managers and employees receives a monetary reward proportionally to the percentage of goals achievement.

\section{Findings: Managers' topoi and PMS in TRA}

In the TRA the three hierarchical levels - politicians, Top managers and Middle managers - have different perceptions of the organization, their jobs and consequently of the PMS. As soon as we are going to focus on the operative part, politicians' reality will not be deepened in this work.

\subsection{Top Managers' Topos}

In Italian Region Authorities, politicians appoint Top Managers, hence their mission is mainly to comply with them and through them, indirectly, with citizens. The role of Top Managers is to drive the organization towards the achievement of strategic long-term goals defined by politicians; such goals are supposed to answer to citizens' needs. Hence their activity is oriented towards the long term period. Their goals are often broad, expressed in terms of outcome, both in the Strategic Plan and in their Annual PMS. To achieve strategic long term goals they transfer the political objects received to the organization. Sub-objects are then defined and short term operative goals, with the related tasks, are assigned to lower organizational positions. This is confirmed by a Middle Manager saying that:

“Top Managers are only an expression of politicians’ will, while we perform operations” (Middle Manager Tourism promotion and development Sector)

\subsubsection{Facts}

Top managers act in a complex and changing environment determined by politicians' requirements and unexpected events. As an example the Top Managers of the Legal Support Direction and the Environment Direction describe how politicians and unexpected events determine complexity.

"Our strategic goal is to provide legal support and advice to the entire Region. Understanding how to get a goal is complex because our goals are not simple and must consider the strong political influence” (Top Manager - Legal Support Direction)

"Unexpected events are the "rule". As an example the curt sequesteres the documents related to a legal procedure, but we have to continue to work on that procedure without any document. They [the court] guarantees to give us back the documents in a few days but after four months they still have our documents. In other words we have to work in this complex situation and such complexity is very difficult to manage” (Top Manager - Environment Direction)

The Top Manager of the Legal Support Direction furthermore describes how the high number of politicians, according to his experience, determines a complex environment because of the need of organizing many meetings for making decisions.

"We have managers and politicians and the number of politicians is higher than the number of managers. The mediation with politicians determines a multiplication of meetings which increases the length of the decision making process and worsens the result” (Top Manager - Legal Support Direction)

A further example of how politicians change idea and determine many problems and a changing environment is provided by the Top Manager of the Competitiveness Direction: 
"The relation with politicians has an impact on our work, because politicians say "We want this street" and one minute later they say "We don't' want this street”...I can't decide” (Top Manager - Competitiveness Direction)

Another element of complexity is given by the number of regional offices and public entities, such as Municipalities and Service providers, involved in the processes and contributing to the attainment of strategic goals. The complexity of the environment described above contrasts with the rigidity of the organizational structure and people working in the TRA. The following sentences underline the inadequacy and rigidity of the organization to the complex and changing environment.

"The organization is complex and should be improved: it is based on a high number of people and tasks in a continuous evolution. This system is not organized and codified to manage this complexity. Maybe we need a method to manage this complexity" (Top Manager - Environment Direction)

"Outside things are changing very fast. Politicians deal with this changing environment asking solutions to the Regional Authority which, on the contrary, is slow because it is organized to be slow" (Top Manager Financial Direction)

Also people working in the TRA is perceived by Top Managers as rigid and inadequate to the complex and changing environment:

"Criticalities exist mainly in the culture. People doesn't' like to approach to problems in a manner different from the usual. They say "We have always work in this way, why should we change?" [...] They don't like to go beyond. For example, if to conclude a task they have to collaborate with too many people, of which some unknown, it happens that they do not realize the task. But in this way things are not concluded because nobody takes care to manage the whole process" (Top Manager - Financial Direction)

\subsubsection{Communication}

In Top Managers' view the achievement of organizational goals, as defined by politicians, requires a flow of communication between politicians and Top Managers and between Top Managers and lower organizational positions. As confirmed by Top Managers, the communication with politicians and lower organizational positions is frequent and high. As an example the Top Manager of the Financial Direction declares the importance of involving lower organizational positions and activating a process of discussion and sharing of goals:

"In our direction there are two, three, four goals that come down from the Direction, through the Department, to Sectors where they are more detailed. Goals are discussed and shared with employees" (Top Manager - Financial Direction)

\subsubsection{Values}

The complex and changing environment faced by the TRA requires flexibility, in terms of ability to change, and professionalism of employees as they, and their competencies, are required to adapt to the change. These are also the most important values in the eyes of the Top managers. In their view pursuing these values may allow to deal with the complex and changing environment and effectively pursue strategic organizational goals:

"In my view, when goals change, the flexibility is an important element...flexibility means to be able to shift from one thing to another one. Only who is flexible can go ahead. Competence is also important, even if specific competences can be bought outside." (Top Manager - Competitiveness Direction)

"These are the most important characteristics: flexibility and ability to change" (Top Manager - Financial Direction)

\subsubsection{Logic}

Top Managers perceive that some elements would support the achievement of organizational goals and should be adequately represented in the PMS. These elements are transversality, collaboration, dynamic goal setting and activity mapping, as described in the following sentences. 
Transversality means that people should overcome the traditional division of the tasks based on specialist competences and be open to perform several different activities, in other words be open to the possibility to acquire new and different competences and tasks. It is also linked to the value of "flexibility", but whereas the latter is referred respect to some sort of change, "transversality" is more required in the daily activities. As an example we report two quotations by the Top Manager of the Healthcare Direction:

"The goal should become "how can I do something" and we should overcome the concept of specialist competencies and be more integrated. But the trend is to propose specialist competencies and not transversal competencies” (Top Manager - Healthcare Direction)

"We have a strong need to organize our structure in a flexible and dynamic manner" (Top ManagerHealthcare Direction)

Another wish in the mind of Top Managers is to create collaboration. Reaching the strategic goals of the TRA requires a complex and long process that involves several actors across different offices. In Top Managers' view people should develop the capability to collaborate by creating teams or by increasing the communication and collaboration, as reported in the following quotation by the Top Manager of the Legal Support Direction:

"I think that we should improve the way teams work. We spend a lot of time in long meetings without any result. Instead, we should work in a way that at the end of the meeting we summarize the discussion and define a conclusion." (Top Manager - Legal Support Direction)

As the Top Manager of the President Staff Bureau suggests, assigning common goals to people participating to the process of achievement of strategic goals may be another way to stimulate higher collaboration between people:

“It will be optimum that certain goals are common to more than one person” (Top Manager - President Staff Bureau Direction)

In the view of Top Managers the complex and changing environment also requires a dynamic goal setting that means that goals are not static but are adapted and changed according to new political priorities or to unexpected events. To this aim monitoring goals during the year is required to verify their achievement and to change goals according to the changed environment, as suggested by the Top Manager of the Land Policies Direction:

"We need elasticity, the monitoring of goals should re-define what we have to do. Monitoring goals is important to adapt goals and not only to verify their achievement” (Top Manager - Land Policies Direction)

The reality model coming from the interviews of TRA Top Managers is then explained and can be represented by the integration of Facts, Values, Logic and Communication as reported in Figure 3. 
Figure 3: Top Managers’ Reality representation

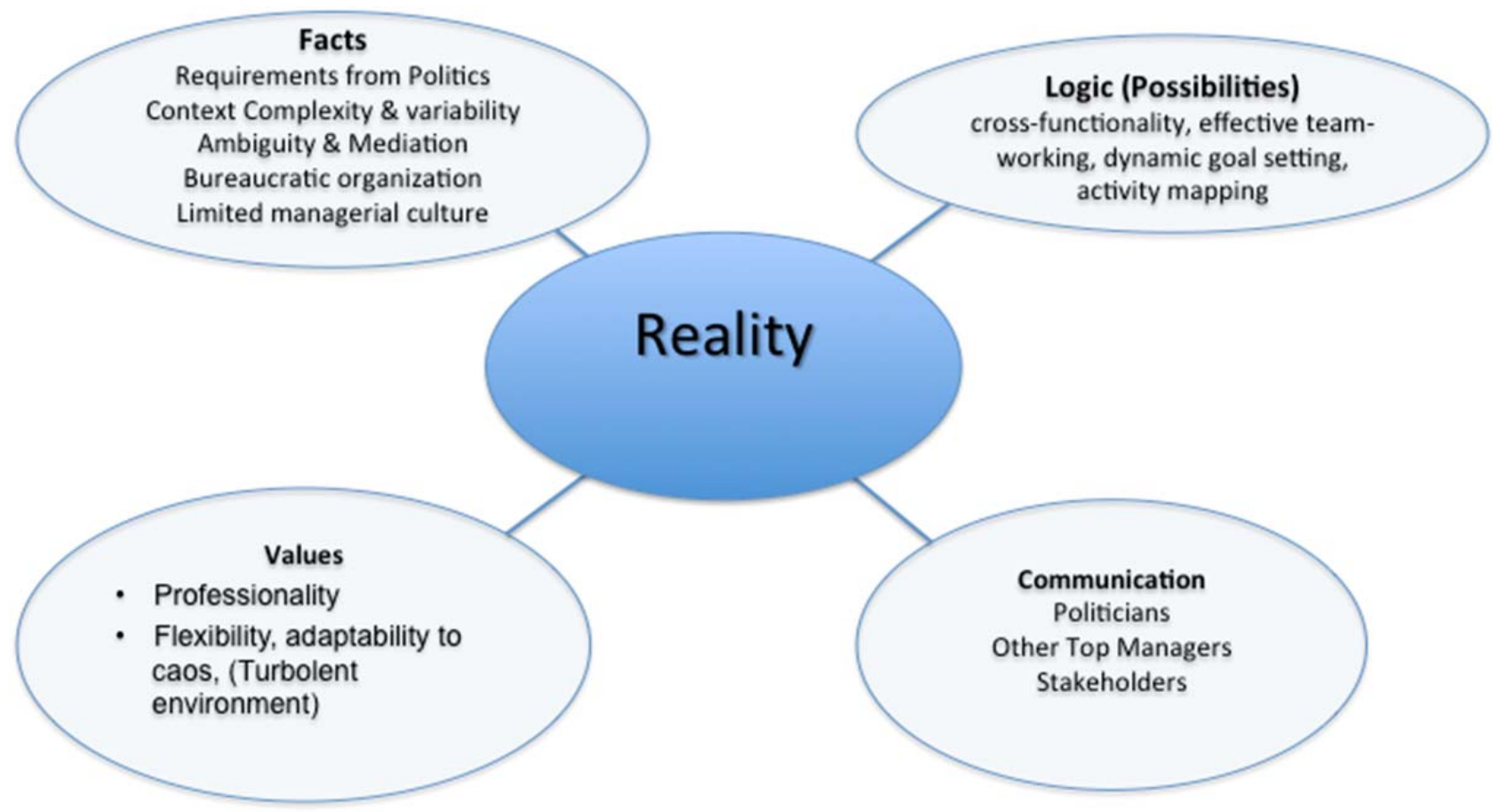

The facts include a changing and complex environment contrasting with the rigidity of the organization and people. On the other side the values of Top Managers - flexibility and professionalism - are coherent with the changing environment, but again difficult to apply because of the rigidity of the organization and people. Correspondently Top Managers wish for higher transversality, effective team working, dynamic goal setting and want to map activities.

\subsection{Middle managers' Topos}

Service providers are appointed by public competition. They contribute to strategic long term goals of the TRA by performing specific and detailed tasks and pursing operative and short term goals. In doing this, they plan, control and ensure the provision of public services to citizens. Their work consists in editing rules and laws, according to politicians, national and communitarian directives, appointing public competitions among service providers and activating procedures to verify that laws, rules and contracts with service providers are respected. They could also provide legal consultancy to other entities.

\subsubsection{Facts}

Middle managers activities are rather standardized, driven by procedures, defining actors and operations, and inspired by the purpose of efficiency and efficacy, as suggested by the following quotations by the Middle Managers of the Agriculture and President Staff Sectors.

"Our sector, the agriculture, is a multi-levels sector: first there are communitarian rules, then there is a set of national and regional rules. Hence the set of rules to apply is big and complex, and this is our main task. All sub-sectors are defined according to the typology of rules, everything is linked to rules" (Middle Manager - Agriculture Sector)

"We have identified precise guidelines with precise deadlines. This means also to be on time. Our work is standardized and this helps us. For example who manage communitarian resources has to follow precise rules that identify documents, actors and resources” (Middle Manager - President Staff Sector) 
As it happens to Top Managers, also Middle Managers act in a complex and changing environment determined by politicians' requirements and unexpected events. The quotations below underline the impact of politicians and unexpected events in determining a complex and changing environment.
“The strong power of politicians shapes our decision” (Middle Manager - Local Public Transport Sector)
"A change can depend on a new need or on a change in the board of politicians. There could be a new decree to apply or a sudden flood in a city. These events are unpredictable and difficult to measure" (Middle Manager - Environment and Territory Sector)

Another element of complexity is given by the number of entities (Municipalities and other Service providers) and regional offices involved in processes and contributing to strategic goals.

"I had to identify a person becoming responsible to maintain the relationships with other colleagues, Municipalities ect" (Middle Manager - Environment and Territory Sector)

\subsubsection{Communication}

Facts described above remark the complex situation Managers have to face every day, and this demonstrates the importance of communication. First the number of entities and regional offices involved in processes requires an intense flow of communication between offices and the TRA and between external entities and the TRA. Secondly the deployment of strategic goals in the organization requires an intense flow of communication between Top and Middle Managers. According with Middle managers' perceptions, they feel some main issues in the field: critical relationships and communication with extra-regional authorities, communication between Regional offices, lack communication between Top Managers and lower positions, and unclear linkage between strategic and operational goals.

The following quotation introduces the problem of the critical relationships and communication with extraregional authorities. This problem often limits the activities of the TRA and the possibility to achieve goals and pursue efficient and effective processes.

"This is the main problem among all problems! For example the cathedral of Pisa is the second most visited museum after the museum of Uffizi in Florence, it is a great business...I had several meetings in Pisa and proposed to do a single ticket usable for both museums. But we are as a vase made of earthenware speaking with vases made of iron. There is not integration between Municipalities. Now we are trying to propose a common plan for all the 600 museums of the region, let's see.” (Middle Manager - Culture Sector)

Problem of communication are present not only among Regional offices and external parties but also between Regional offices. These issues, together with the critical relationships and communication with extra-regional authorities, limit activities and the achievement of goals.

"People prefer working in their own area with their own plans. Problems arise when they are required to change their plan to face other people priorities.” (Middle Manager - Culture Sector)

Goals are related to specific activities and measure output, efficiency and input. These short term goals are linked to strategic goals, hence communication between Top Managers and lower positions is important for the deployment of strategic goals and the clarity of tasks and related operative goals. The lack of communication between Top Managers and lower positions makes unclear the linkage between strategic and operational goals. This linkage results unclear and not strong enough, because the identification of these goals is not based on a real negotiation between Middle and Top Managers.

"We should better share goals...the sharing of goals with Top Managers doesn't' exist. We should improve the planning process because it is not possible to have the same broad goals of Top Managers simply replicated for the lower Middle Managers. In this way the evaluation of the contribution of people to the achievement of goals is impossible" (Middle Manager - Culture Sector)

"Strategic goals are often directly allocated to us, without any discussion even if we don't have the tools to control such goals" (Middle Manager - Legal affairs for the environment and the territory Sector) 


\subsubsection{Values}

Compliance with rules is the most important value for Middle Managers. Like Top Managers, flexibility and professionalism of people are other important values. Finally the collaboration between Regional offices and with other entities (Municipalities and other service providers) results crucial in the work of Middle Managers.

Following precise rules and procedures is considered to be fundamental for Middle Managers. They think that following certain procedures will produce the expected results, as suggested by the following quotations.

"When we have organized our area I decided that to coordinate the area we needed rules and laws" (Middle Manager - Culture Sector)

"We identified procedures with precise rules and deadlines. Comply with deadlines is important. Our work is standardized, and this plan helps us a lot.” (Middle Manager - President Staff Sector)

"Our sector, the agriculture, is a multi-level sector: first there are communitarian rules, then there is a set of national rules, and then regional rules. So the set of rules to apply is wide and complex, and this is our main task." (Middle Manager - Rural Development Department)

"We have deadlines and we have to comply with them..." (Middle Manager - Social and Regional Health System Department)

They mainly define contracts and rules to apply to services providers, but the citizens' satisfaction is not verified. They are oriented only to a part of the whole process (the definition of rules and contracts). We report the example of the “Local Public Transportation” Department with respect to the relationship between the Regional Authority, which provides contract and guidelines, and providers of services to citizens.

"Our input [for providers] is a plan and some guidelines. They [the providers] define a proposal for the provision of services and we verify that the proposal is coherent with plans and guidelines. We verify citizens' satisfaction on the service using the income as a proxy" (Middle Manager - Local Public Transportation Department)

The flexibility and professionalism are other important values. According to the Agriculture Sector Middle Manager, in the changing and complex environment people should be able to face new and unexpected tasks:

"I appreciate a lot the flexibility of people. As the number of employees is lower than some years ago, a higher availability from all employees - both managers and lower positions - is required. They should understand that if there is something new to face they should be available" (Middle Manager-Agriculture Sector)

The Collaboration with other employees among the TRA is important as well, because the achievement of strategic goals is a complex process which requires the involvement of different Regional offices and external entities. The following quotations by the Middle Managers of the Environment and Energy Sector and the Mobility and Infrastructure Sector refer, respectively, to the importance of the collaboration among Regional offices and between the Region and other entities.

"Involving employees in the achievement of goals is a need, we can't work in another way" (Middle Manager - Environment and Energy Sector)

"These issues are linked with several entities outside the Region. The impact on citizens depends also on the work of these entities and how well we work together" (Middle Manager - Mobility and Infrastructure Sector)

Even if flexibility is required, the TRA organizational structure and the PMS are rigid. Many employees are concentrated to satisfy their own precise tasks and frequently they act by considering only their Department or Direction. In this way it is difficult to be flexible. 
"We are a hierarchical and functional organization, we are separate entities. Also the Performance Management System works in this way, it is not adequate" (Middle Manager - President Staff Bureau Department)

"Our system is divided into many boxes and everyone has his one with his activities and goals" (Middle Manager - President Staff Bureau Department)

\subsubsection{Logic}

Even if Middle Managers activities have an impact on the short term, they need to have a wider view of the long term period. Their goals are enough specific but always attributable, at a higher hierarchical level, to the related Top manager objective or to the higher Regional strategic objective. Middle Managers perceive that there would be an improvement in the system and a better result if the work would be more collaborative, transparent, adequately rewarded, credible and positively influenced by politicians.

In the mind of Middle managers collaboration is an important value, hence they wish even a higher collaboration between Regional offices and between the Region and external entities.

"There is an organizational problem. We have a hierarchical and functional structure. We should be more transversal, both in terms of approach to the work and in terms of tools such as the performance measurement system” (Middle Manager - President Staff Sector)

"It is more and more necessary to analyze my units and external entities who perform part of the process in an integrated way” (Middle Manager - Tourisms, Trade and Territory Sector)

Middle Managers also think that the organization is not transparent and they wish higher clarity about what people do, as declared by the Middle Manger of the Social and Regional Health System Department.

"If you ask to ten people if our structure is transparent, I'm sure that nine of them will answer "No, it isn't'”. We should find a system where people recognize themselves and their work. Employees do not recognize themselves and what they do in our system" (Middle Manager - Social and Regional Health System Department)

Middle Managers also think that rewarding would improve the way people works. Rewarding people doesn't only include an increase in the salary but it could also involve other form of non-economic incentives, as suggested by the Middle Manager of the Social and Regional Health System Department.

"Our reward system includes career progress and increase in salary. Other forms of incentive could be to pay a travel, to allow to the employees to do an activity he/she likes or to allow remote working. We only need imagination" (Middle Manager - Social and Regional Health System Department)

Credibility is linked to the controllability of goals by people and to the identification of challenging goals. This would increase the motivation of people to perform activities to achieve their goals.

"We should create goals that are as much achievable as possible. For example, a critical point in my unit, is an increase in the efficiency of expenses and investments" (Middle Manager - Culture Sector)

The controllability of goals is also linked to the influence of politicians who may change goals and influence the work of employees. In this respect Middle Managers think that employees should be evaluated on the capability to perform the part of the tasks assigned to them and whish for a separation between the autonomy of politicians and the autonomy of technicians. It is important that sudden changes in the goal of the politicians do not affect the goal, and the consequent successful attainment of such goals by the Managers.

“Today politicians assign certain goals, for example to produce a document in six months. I write the document within the deadline, but then within the six months politicians change their goal for certain reasons and they do no more need the document. I should be considered successful in the attainment of the goal. For this reason I would like a separation between my autonomy and the autonomy of politicians and between the responsibility of politicians and technicians” (Middle Manager-Mobility and Infrastructure Sector) 
The reality model coming from the interviews of TRA Middle Managers is then explained and can be represented by the integration of Facts, Values, Logic and Communication as summarized in Figure 4.

\section{Figure 4: Middle Managers’ Reality representation}

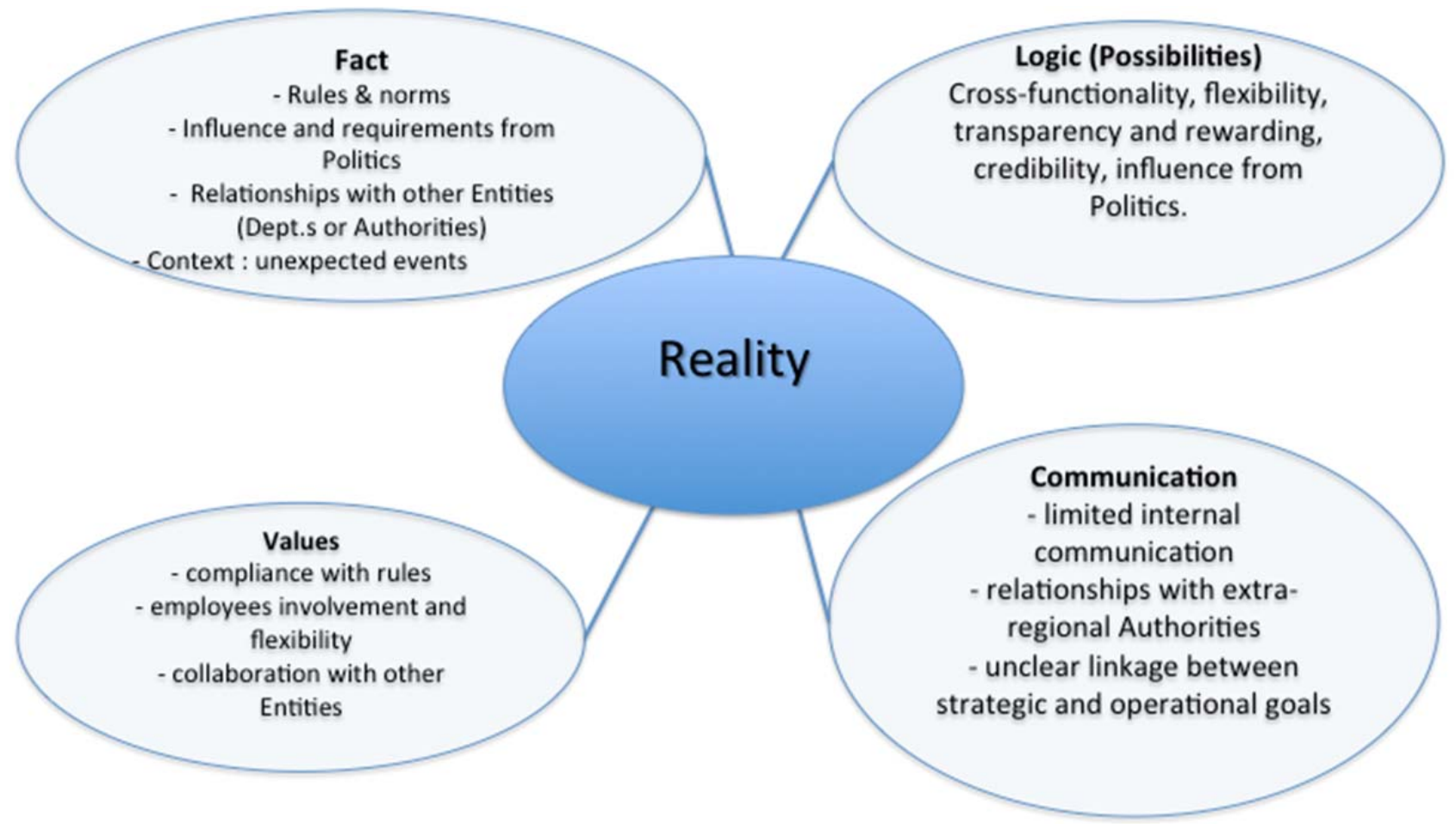

\subsection{Top and Middle Managers’ perception of Performance}

According to Top managers' opinions, the actual Performance management system negatively reflects the rigidity of the organization and of people. Goal setting does not represent processes and targets are mainly static. The present system is consequently inadequate to represent the work of the people involved. The complexity of Top Manager topos and the incoherencies described above make the design and the realization of an adequate performance management extremely difficult.

For example, the Top Manager of the Environment Direction recognizes the inability of the performance management system to measure how the work is performed according to his values, i.e. the team working and the professionalism.

"Our activities and their complexity are difficult to measure. It is very difficult, because our work consists in investigations, intellectual work and collaboration” (Top Manager - Land Policies Direction)

Further difficulties in measuring the achievement of strategic goals are highlighted also by the Top Manager of the Financial Direction. In his view, it is hard to measure strategic goals because they involve complex evaluations difficult to be represented with numbers. Furthermore the inability of the PMS to represent processes makes unclear the evaluation of the contribution of people to the achievement of strategic organizational goals.

"...something should be measured, this is the problem. In some cases it is easy, for instance how much paper has been consumed. But measuring the achievement of goals linked to the strategy and political choices is very difficult" (Top Manager - Financial Direction)

Some values, such as flexibility, are also difficult to measure with numbers as the Top Manager of the Healthcare Direction underlines.

"The decree on ticket emanated by the National Parliament on the $4^{\text {th }}$ of August, during summer holidays, to be converted in Regional Law and adapted to our Region within a day, has been a challenge. People 
renounced to their holidays but I don't have any specific measure to evaluate their behaviour. I don't have any measure to reward the availability of people and underline their capacity to rapidly answer to this need. Doing something discretely in 20 days is better than doing something perfect in 60 days." (Top ManagerHealthcare Direction)

Nevertheless, even if the need of a performance management system is felt by Top Managers, some level of discretionarily, flexibility of the system and some way to face the need of goal revisions during the year is also required. For example the Top Manager of the President Staff Bureau Direction suggests to make the system more flexible and reducing rigidity by allowing the possibility to update goals during the year.

"Maybe one solution would be to give the possibility to update goals more frequently and give the opportunity to include new goals according to unexpected events and emerging priorities that have happened during the year" (Top Manager - President Staff Bureau Direction)

With respect to the difficulties in measuring the professionalisms and the intellectual work as well as the availability of people to answer to unexpected events and new priorities, the Top Manager of the Legal Support Direction suggests some process measures, such as time spent in the activity or customers' satisfaction. These measures particularly fit the Legal Direction as it provides staff support to most of the Regional offices, which represent their customers.

"We can measure the time employed to perform the activity according to its level of complexity, or we can measure the satisfaction of our customers, for example by using a questionnaires.” (Top Manager - Legal Support Direction)

The Top Manager of the Environment Direction suggests more discretionarily and subjectivity in the evaluation of performance by adopting a qualitative evaluation of the work done by an employee.

"There is also the opinion on a person. Someone could have great knowledge, capabilities and competencies and perform a high quality work, someone else could have the same knowledge but not the same capabilities and competencies and perform a worse work. This is not measurable, so we can introduce more discretionarily in the evaluation, for example we can use a 1-5 scale." (Top Manager - Land Policies Direction)

Coherently with the perception of the Performance Management System by Top Managers, the Middle Managers feel even more uncomfortable with the actual PMS. The latters perceive the concept of performance as extremely difficult to be defined and measured in their context, and consequently the actual PMS is judged useless, too bureaucratic and not convincing. The most important concerns are on the rigidity of the mechanism and on the presence of outcome measures in the system.

Middle Managers think that PMS is bureaucratic and requires a lot of work, despite its limited usefulness.

\footnotetext{
"Today the performance management system is a sort of bureaucratic and heavy work. It is simply a fulfilment" (Middle Manager - Culture Sector)
}

"I'm quite sceptic about the need to put everything into a precise evaluation mechanism” (Middle ManagerAgricultural production Sector)

"Assigning outcome goals to people performing operations is not acceptable and understandable. The available resources, activities to perform and the required outputs are not sufficiently likeable to outcome." (Middle Manager - Sector Research and Studies)

One of the reasons of this judgment on the uselessness of the PMS is also linked to the limited communication between Top and Middle Managers. Middle managers goals are related to specific activities and measure output, efficiency and input. Such goals, basically of short term, represent the deployment of strategic goals. However, from Middle managers' perspective, the linkage between strategic and operative goals is not strong, nor clear or accepted. According to them the process of identification of these goals is problematic because it is not based on a real negotiation between Middle and Top managers; what middle managers often sustain is a lack of communication. The personal contribution to the attainment of the goal is further a missing element of the system. 
"The system has never been understood and accepted even from the higher levels. They simply delegate all tasks to lower positions” (Middle Manager - Tourism development and promotion Sector)

"The actual performance management system does not represent sufficiently our contribution to strategic goals” (Middle Manager - President Staff Sector)

The final consideration of the Middle Manager of the Rural Development Department effectively summarises the perception of Middle managers on the Performance management system:

"What system? ... The performance management system is highly useless and doesn't work. It is not useful to evaluate the productivity and flexibility of personnel. It cannot be used, for example, to evaluate and reward who works overtime to solve problems” (Middle Manager - Rural Development Department)

\section{Discussion}

Different realities (and performance concepts within them) rise from the description above. The picture in Figure 5 compares and summarizes the main features.

Figure 5: Top and Middle Managers’ Reality summary

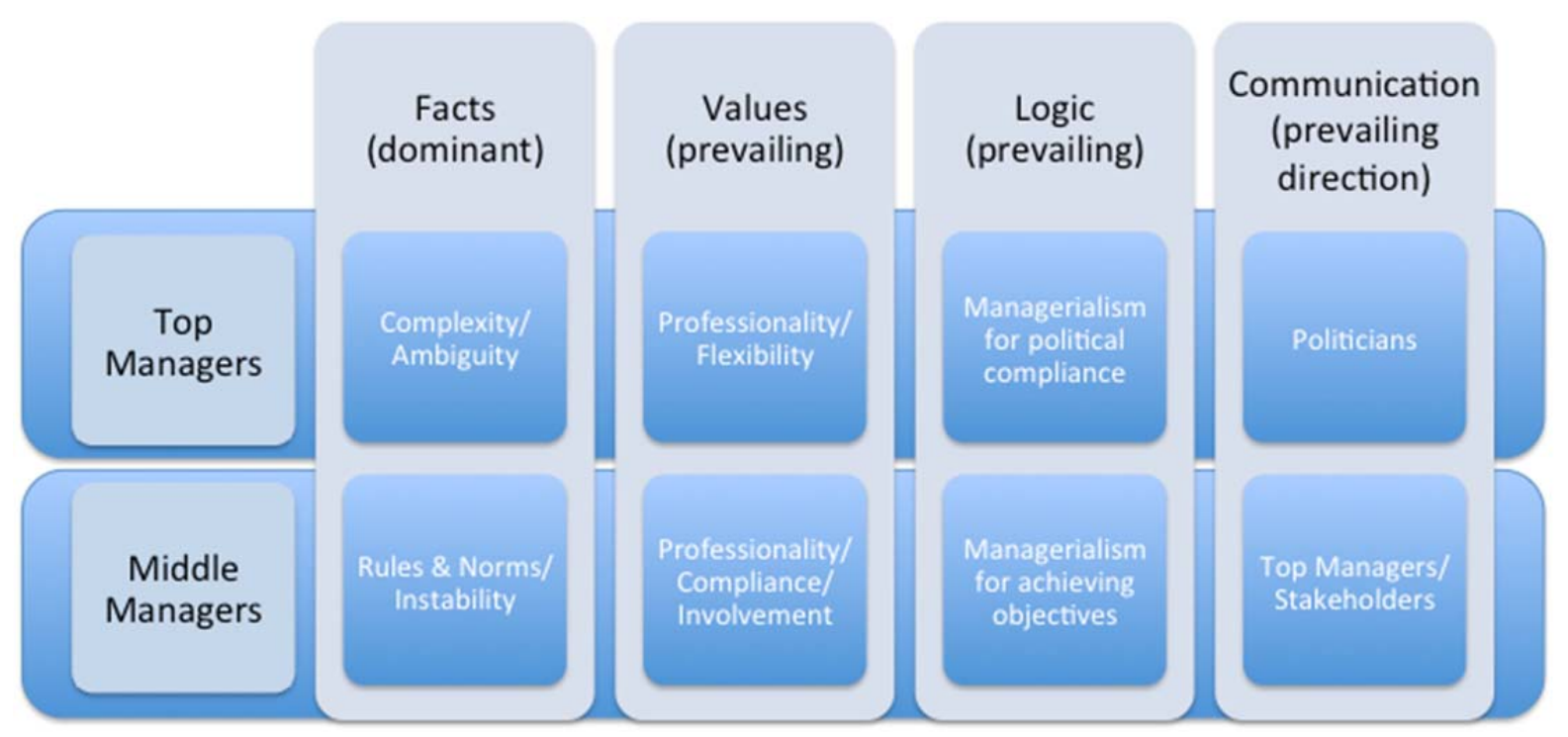

The complexity of a turbulent environment in term of change in national laws, financing rules, economic policy and national budget targets, and the ambiguity deriving from the contiguity to elected politicians, which often creates pressures toward blurred goals, are the contextual elements of Top Managers of TRA. High professionalism and flexibility assume a major relevance to them and their logic can be defined as "managerialism" for political compliance", in the sense that their managerial abilities are highly committed to comply with political requests. This is also a concern related to the rules of recruitment of Top managers by the regional authorities, where the politicians in charge directly recruit Top managers. As a consequence, communication is mainly geared toward policymakers and politicians.

On the other hand, Middle managers strongly feel the need to adhere to the rules in their administrative action, both for their legal and technical cultural background, and for the need of legal protection required in their work. Nevertheless, a critical point is that the required stability of the rules clashes against the instability of daily context to manage. In this sense, flexibility is also felt as an important value for Middle managers, and the need for an increasing commitment with respect to Top managers goals, flexibility and professionalism in the way of organizing work emerge as values. Middle managers act by "managerialism for achieving objectives", in the sense that their decisional level requires the definition of specific targets related to objectives of functional area that may drive their managerial action. The influence of politics exists, but the reference to planning is prevalent. The direction of communication is therefore 
toward Top managers to require input for their action, and towards external stakeholders (local authorities, public and private entities etc.) with which they constantly interact with for the provision of services.

The perception of performance and of the existing PMS are different on the two levels, while presenting some common aspects. They both acknowledge the difficulty in measuring performance in the context of a regional agency, as a consequence of the typology of activities (services, issuing of norms) and the complexity in identifying relevant variables and measuring them. Moreover, in their view, the current system does not have the flexibility to cope with the rapid changes in the operating environment of the administration.

In the view of Top management the main aspects that makes performance measurement difficult is the undefinability of objectives depending by the influence of politics on their action. The Middle management points the finger on the scarce involvement in made by Top Managers with them, both in setting the goals, and in the managerial stage of processes. This lack of communication creates two main consequences. The first is that Middle Managers perceive Top managers as the expression of political power. The second is that Middle Managers fear the use of outcome indicators, as the contribution of their actions to the achievement of targets cannot be clearly recognized. In particular they express criticalities with respect to the process of negotiation of goals and discussion of results. The process of definition of goals is perceived as top-down: Top managers directly assign their goals to the lower levels and the possibility to re-define goals is not sufficiently sponsored, some managers even don't know about this possibility. Top managers are not sufficiently committed to diffuse the importance of the PMS: the result is that the PMS is perceived as a formality, not useful for decision making. Further, there is not a process of discussion of results with lower levels.

The criticism of middle managers against the current PMS in TRA is stronger than Top managers: they feel the importance of the system to orient their activity, but the current system is perceived as not flexible, scarcely sponsored by the Top management, with low commitment both in defining goals and in discussing results with lower levels (top down process).

The limitations of the current system are rooted in the lack of understanding of the different topoi related to the different managerial levels and the different perceptions of performance. Top managers feel the compliance to politicians as fundamental; flexibility in matching changing goals is the most important feature in this respect, and consequently one of the strongest limitations of the current PMS. Capturing the blurred goals frequently given to them is also difficult to translate in term of specific objects and quantified target and this represents another PMS criticism. They do not recognize a lack of involvement of the lower levels in the planning process; on the contrary, some of them claim their effort to involve. Middle managers need objectives from Top managers and require involvement in their definition and in the subsequent process of realization. They identify the lack of the current system mostly in its inability to link strategic objectives, outcome and resources to operations, and the fact that the overall control process is not involving them.

The direction of communication is clearly diverging: Top managers mainly towards politicians, middle managers towards Top managers and external stakeholders. This creates shortage of dialogue and poor sharing of goals and, in the end, the lack of a common space of meaning and understanding. Although objectives might be achieved with the current system, the internal climate suffers by these limitations of PMS and the system itself is highly criticized.

\section{Conclusions}

This research, supported by the pragmatic constructivism, wishes to contribute to the literature around the performance measurement in the public sector. The pragmatic constructivism helps to shed light on the complexity of public organizations with multiple decisional levels, working in changing and complex environment, by the analysis of facts, possibilities, values and logic of organizational actors.

Results show that different topoi have different concepts of performance. Different topoi may cohabit within the same organization, according to different organizational positions. This does not constitute a problem if communication between different topoi exists to build a bridge between them and the associated concepts of performance. If communication does not exist, the different topoi will not find any point of convergence and the different concepts of performance will remain disaggregated and diverging (as the case described in this paper). The effect will be that the PMS will be ambiguous and actors will pursue their own goals according to their topoi. On the opposite, communication will help to integrate different concepts of performance and the PMS will result enriched because it will incorporate both the political and the technical issues as the two souls of a public authority.

Previous researches also underlined that when different groups of actors conflict to determine organizational performance criteria according to their interests (Scott, 1995) the most powerful actors will determine the outcome of 
change (Pettigrew and Whipp, 1991) and will solve conflicts by the use of power (Pfeffer, 1992; Walsh et al., 1981). Again, the most powerful actors, in terms of organizational positions, will lose their power to influence change when communication doesn't exist. They can use the power to impose a change but if they are not able to convince the other actors, the latter will only comply with change only as a merely bureaucratic fulfilment, without convincement. In this sense, the absence of communication also reduces the power of Top managers, while communication may help them to confirm their role as "leader”. Again the PMS will result ambiguous without communication.

The issue of "communication” appears crucial and fundamental to embrace the process of redesign of PMS in a complex environment. In fact, "Communication provides access to facts, logic and values through dialogue with other people. Communication is the link that binds reality together. The problem with communication of course is that we often tend to misunderstand each other. When we do this it is because there are parts of other people's realities that we do not comprehend. Hence, we misinterpret reality.” (Henriksen et al., 2004: 22). Although involvement has been questioned as a mean of consensus-building that will invariably lead to top-down alignment of goals, performance indicators and organizational action (Modell, 2004), the possibility to develop communication implies involvement.

Results of this paper underlines that communication has a double effect. On the one hand, communication will help to develop PMS able to represent the complexity of the work of public organizations thanks to the integration between different topoi and in particular between higher and lower organizational positions. Secondly, although this seems to reduce the power of higher levels by accepting a compromise with lower levels, it actually reinforces their role of leaders thanks to the increase in credibility in the eyes of lower levels and to a more committed action by them, away from the merely formal compliance as in absence of communication. 


\section{References}

Aidemark, L.G. 2001. The meaning of balanced scorecards in the health care organization. Financial Accountability and Management,17(1): 23-40.

Arnaboldi, M., Palermo, T.2011. Translating ambiguous reforms: doing better next time? Management Accounting Research, 22(1): 6-15.

Auerbach, C., Silverstein, L. 2003. Qualitative Data: An Introduction to Coding and Analysis. New York, NY: University Press.

Besanko, D., Dranove, D., Shanley, M. 1996. The Economics of Strategy. New York, NY: Wiley.

Bloor, M., Frankland, J., Thomas, M. Robson, K. 2001. Focus Groups in Social Research. London: Sage.

Brignall, S., Modell S. 2000. An institutional perspective on performance measurement and management in the 'New Public Sector'. Management Accounting Research, 11 (3): 381-206.

Bromwich, M., Lapsley, I. 1997.Decentralization and management accounting in central government: recycling old ideas? Financial Accountability and Management, 13(2): 181-201.

Cavalluzzo, K.S., Ittner, C.D. 2004. Implementing performance measurement innovations: evidence from government. Accounting, Organization and Society, 29(3-4): 243-267.

Chapman, C., Cooper, D.J., Miller, P. 2009. Accounting, Organizations and Institutions: Essay in Honor of Anthony Hopwood. Oxford: Oxford University Press.

Covalesky, M.A., Dirsmith, M.V. 1981. MBO and goal directedness in a hospital context. Academy of Management Review, 24(3): 409-418.

Harvey, D. 1995. Re-engineering: The Critical Success Factors, $2^{\text {nd }}$ edition. London: Business Intelligence Ltd.

Henriksen, L. B., Nørreklit, L., Jørgensen, K. M., Christensen, J. B. \& O’Donnel, D. 2004. Dimensions of Change. Conceptualizing Reality in Organisational Research. Copenhagen: Copenhagen Business School Press.

Hood, C. 1995. The "New Public Management" in the 1980s: variations on a theme. Accounting, Organizations and Society, 20(2/3): 99-109.

Hooghe, L., Marks, G, Schakel, A. 2010. The Rise of Regional Authority. A Comparative Study of 42 Democracies. London: Routledge.

Hopwood, A.G. 1972. An empirical study of the role of accounting data in performance evaluation. Journal of Accounting Research, 10(2): 156-182.

Humphewy, C., Miller, P., Scapens, R.W. 1993. Accountability and accountable management in the UK public sector. Accounting Auditing and Accountability Journal, 6(1): 7-29.

Hyndman, N., Eden, R. 2000. A study of the coordination of mission, objectives and targets in U.K. executive agencies. Management Accounting Research, 11(2): 175-191.

Jakobsen, M., Johansson, I.-L., Nørreklit, H. \& (Eds.) 2011. An Actor's Approach to Management. Conceptual Framework and Company Practices. Copenhagen: DJØF Publishing.

Kaplan, R.S. 2011. Strategic performance measurement and management in non-profit organizations. Nonprofit Management and Leadership, 11(3): 353-370.

Klott, L. 2002.Performance management and measurement in universities: a case study. Paper presented at the $25^{\text {th }}$ annual congress of the European Accounting Association (Copenhagen).

Kurunmaki, L., Miller P. 2006.Modernising government: the calculating self, hybridization and performance measurement. Financial Accountability and Management, 22(1): 87-106.

Lapsley, I. 2001. Management accounting and the state: making sense of complexity. Management Accounting Research, 11(2): 169-173.

Likierman, A. 1994. Management accounting in UK central government - some research issues. Financial Accountability and Management, 10(2): 93-116.

Llewellyn, S. 1996. Performance management in the social service: its meaning and measurement. In Lapsley I. and Mitchell F. (Eds.), Accounting and Performance Measurement. Issues in the Private and Public Sectors. London: Paul Chapman Publishing.

Matland, R. 1995. Synthesizing the implementation literature: the ambiguity-conflict model of policy implementation. Journal of Public Administration Research and Theory, 5(2): 145-174.

Mitchell, F., Nielsen, L.B., Nørreklit, A. Nørreklit, L. 2013. Scoring strategic performance: a pragmatic constructivist approach to strategic performance measurement. Journal of Management and Governance, 17(1): 5-34.

Modell, S. 2003. Goals versus institutions: the development of performance measurement in the Swedish university sector. Management Accounting Research, 14(3): 333-359.

Modell, S. 2004. Performance measurement myths in the public sector: a research note. Financial Accountability and Management, 20(1): 39-55.

Nørreklit, H., Nørreklit, L. \& Mitchell, F. 2010. Towards a paradigmatic foundation for accounting practice. Accounting, Auditing \& Accountability Journal, 23(6): 733-58. 
Nørreklit, L., Nørreklit, H. \& Israelsen, P. 2006. The validity of management control topoi. Management Accounting Research, 17(1): 42-71.

Osborne, D. and Gaebler, T. 1991. Reinventing Government. New York, NY: Plume.

Otley, D. 1999. Performance management: a framework for management control systems research. Management Accounting Research, 10(4): 363-382.

Ottaway, R.N. (1983), The change agent: a taxonomy in relation to the change process. Human Relations, 36 (4): $361-$ 392.

Panozzo, F., 2000. Management by decree. Paradoxes in the reform of the Italian public sector. Scandinavian Journal of Management, 16(4): 357-373.

Pettersen, I.J. 2001. Budgetary control of hospital ritual, rhetorics and rationalized myths. Financial Accountability and Management, 11(3): 207-221.

Pettigrew, A., Whipp, R. 1991. Managing Change for Competitive Success. Oxford: Blackwell.

Pfeffer, J. 1992. Managing with Power: Politics and Influence in Organizations. Boston: Harvard Business School Press.

Poister, T.H., Streib G. 1995. MBO in municipal government: variations on a traditional management tool. Public Administration, 55(1): 48-56.

Puxty, A.G. 1993. The Social and Organizational Context of Management Accounting. New York, NY: Academic Press

Scott, W.R. 1995. Institutions and Organizations: Theory and Research. London: Sage Publications.

Seal, W. 2012. Some proposals for impactful management control research. Qualitative Research in Accounting \& Management, 9(3): 228-244.

Simons R. 1991 Strategic orientation and top management attention to control systems. Strategic Management Journal, 12(1): 49-62.

Waggoner, D.B.; Neely A. D.; Kennerley M. P. 1999. The forces that shape organizational performance measurement systems: an interdisciplinary review. International Journal Production Economics, 60(1): 53-60.

Walsh, K., Hinings C.R., Greenwood R., Ranson, S. 1981. Power and advantage in organization. Organization Studies, 2(2): 131-152.

Weiss J.A. 1996. In the state of public management. In: Psychology. D. F. Kettl and H. Brinton Milward, pp. 118-142. Baltimore: Johns Hopkins University Press.

Wright B.E. 2007. Public service and motivation: does mission matter? Public Administration Review, 32(1): 54-64.

Yin, R. 2003 Case study research: Design and methods. London: Sage Publications. 